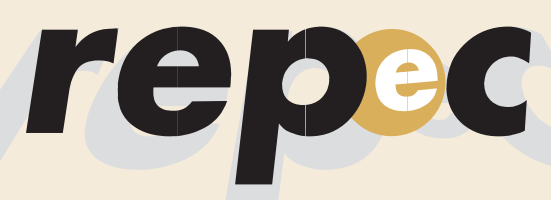

REPeC, Brasília, v. 9, n. 2, art. 4, p. 182-199, abr.jun. 2015 Disponível online em www.repec.org.br DOI: http://dx.doi.org/10.17524/repec.v9i2.1173
Revista de Educação e Pesquisa em Contabilidade Journal of Education and Research in Accounting Revista de Educación e Investigación en Contabilidad

Periódico Trimestral, digital e gratuito publicado pela Academia Brasileira de Ciências Contábeis

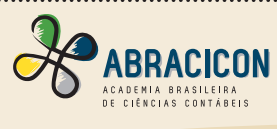

\title{
Disclosure e Accountability nas Demonstrações Contábeis Públicas como Instrumentos de Controle Social
}

\section{Resumo}

A contabilidade pública tem como um dos seus objetivos suportar a instrumentalização do controle social. Com efeito, este trabalho tem por norte discutir: Como melhorar a compreensibilidade, pelo cidadão médio, sobre a informação contida nas demonstrações contábeis públicas? Destarte, temse como objetivo conhecer o nível de entendimento dos líderes comunitários da cidade de Curitiba sobre as informações extraídas do Balanço Orçamentário. A pesquisa se valeu da análise documental e pesquisa de campo a partir da aplicação de questionário semiestruturado e tratamento dos dados com o emprego de técnicas de análise uni/bivariada e validação a partir do emprego do teste estatístico $\chi 2$. Desvenda-se que, embora grande parte dos respondentes não procure se informar sobre a utilização do dinheiro público, a grande maioria, afirma ter muito ou médio interesse em conhecer o conteúdo da prestação de contas. Sustenta-se que a dificuldade na busca pela informação está justamente na falta de entendimento da terminologia contábil pública. Como resultado, nota-se que as restrições na comunicação contábil podem ser reduzidas se essa for exposta em linguagem de fácil compreensão, mediada por uma evidenciação complementar que apresente não apenas os resultados, mas a análise e interpretação desses resultados. Assim, espera-se que este estudo preliminar contribua para a construção de um modelo de controle social e seu uso pela sociedade, a fim de ampliar e qualificar a participação do cidadão na gestão da respública. Observa-se, por fim, a necessidade de desenvolvimento da política pública essencial representada pela educação visando à efetiva apropriação social da informação contábil pública.

Palavras-chave: Contabilidade Pública; Controle Social; Disclosure; Accountability.

\section{Sônia Maria Augustinho Mestre pela Universidade Tecnológica Federal do Paraná e contadora na Universidade Tecnológica Federal do Paraná (UTFPR). Contato: Av. Sete de Setembro, 3.165. Reitoria. Bairro: Rebouças. Curitiba-PR. CEP.: 80.230-901. E-mail: soniam@utfpr.edu.br}

\section{Antonio Gonçalves de Oliveira} Doutor pela Universidade Federal de Santa Catarina (UFSC) e professor na Universidade Tecnológica Federal do Paraná (UTFPR). Contato: Av. Sete de Setembro, 3.165. Campus Universitário. Bairro: Rebouças. Curitiba-PR. CEP.: 80.230-901.

E-mail: agoliveira@utfpr.edu.br

\section{Inácio Andruski Guimarães} Doutor pela Universidade Federal do Paraná (UFPR) e professor Adjunto na Universidade Tecnológica Federal do Paraná (UTFPR). Contato: Av. Sete de Setembro, 3.165. Campus Universitário. Bairro: Rebouças. Curitiba-PR. CEP.: 80.230-901.

E-mail: andruski@utfpr.edu.br 


\section{Introdução}

Toda a organização institucional do Estado é financeiramente sustentada por meio de recursos oriundos da população, sendo função primordial desse aporte financeiro promover o crescimento e o desenvolvimento econômico e social visando ao bem comum de seu povo, "acionista majoritário" da res-publica.

Tem-se, então, que o agente público, no aceite da responsabilidade que lhe delega a sociedade, para a realização do bem público, fica obrigado a prestar contas dos atos que em nome da coletividade pratica na realização das responsabilidades sociais do Estado.

Nesse raciocínio, Schedler (1999) ensina que, embora o senso comum diga claramente que a essência da política seja o poder, os teóricos clássicos já sabiam que, na política, primeiro vem o poder e, em seguida, a necessidade de controlá-lo.

No que toca, especificamente, à execução financeira das políticas públicas, essa ocorre por meio das ações orçamentária, financeira e patrimonial; e do planejamento governamental, como fator decorrente da mobilização de técnicas e instrumentos contábeis, que registram e controlam os atos e fatos da gestão pública.

Desta forma, a contabilidade pública é ferramenta de controle social e de empoderamento da sociedade no exercício da democracia, em particular, quando atua nos espaços de participação que lhes são proporcionados pelo próprio Estado.

Entretanto, para que a prática da transparência/evidenciação (disclosure) na divulgação das transações governamentais satisfaça duas de suas finalidades - (i) informar sobre os resultados alcançados e (ii) apoiar a tomada de decisão (Secretaria do Tesouro Nacional (STN), 2012) - faz-se necessário que o cidadão, como usuário da informação contábil pública, também compreenda sua mensagem e tenha condições de exercer o controle social sobre o uso dos recursos públicos.

A partir da Lei de Responsabilidade Fiscal, a administração pública se viu obrigada a dar total transparência à gestão, a fim de instrumentalizar os cidadãos para acompanhar a aplicação dos recursos públicos. Nesse caso as informações contábeis se revelam atributos de primeira ordem para viabilizar a concretização desse objetivo. Nesse contexto, há pelo menos uma questão que merece ser considerada: será que, de fato, as informações contábeis se apresentam de forma compreensível ao cidadão comum? (Dias, 2009, p. 3).

Uma preocupação constante do cidadão para com o Estado é quanto ao volume de impostos consumidos para a prestação dos serviços à sociedade. Tal preocupação prende-se ao fato de que a contabilidade no Estado apresenta resultados que os cidadãos não estão preparados para entender, aumentando, assim, a assimetria entre as informações produzidas pelo agente (Estado) e o entendimento delas pelo principal (cidadão) (Slomski, 2009, p. 99).

Destarte, a linguagem extremamente técnica das demonstrações contábeis pressupõe a sua não compreensibilidade e assimilação por aqueles que não são afeitos ao universo próprio da ciência e técnica contábil.

Para Dias e Nagakawa (2001), muitos termos empregados nas demonstrações contábeis não são compreendidos por seus destinatários ou são interpretados de forma diferente do que se pretendia. Para os autores, se isso ocorre com usuários mais familiarizados com a terminologia contábil o que pode ser dito em relação aos menos tradicionais, como o cidadão comum?

Desta forma, a questão norteadora da pesquisa proposta para este estudo é: como melhorar a compreensibilidade do cidadão médio sobre a informação contábil contida nas demonstrações contábeis públicas?

Para se obter resposta a tal proposição, julga-se que, inicialmente, se faz necessário conhecer: i) o que entende o cidadão sobre a terminologia básica apresentada nos demonstrativos contábeis públicos; ii) qual o interesse do cidadão em buscar a informação contábil pública; e iii) quais formas de apresentação complementar poderiam ser utilizadas para melhorar a compreensibilidade desses demonstrativos, sob o ponto de vista do usuário da informação. 
Ainda, tomando-se por base as colocações de Batista (2010), para quem o excesso contemporâneo de informação não deve se desvincular do saber informar-se, processo que envolve uma situação constante de aprendizagem, coloca-se como hipótese (h) a ser testada: a educação formal tem influência na compreensibilidade da informação contábil pública compartilhada pelo Estado.

Assim, diante da importância da informação para a correta tomada de decisão e considerando o próprio objetivo da Contabilidade, que é comunicar, esta investigação tem como objetivo geral conhecer o nível de entendimento dos líderes comunitários da cidade de Curitiba acerca da prestação de contas dos agentes públicos a partir das informações extraídas do Balanço Orçamentário.

O trabalho está estruturado em seis seções: a primeira é esta breve introdução, seguida pela fundamentação teórica na segunda seção. Na terceira é apresentada a metodologia utilizada na pesquisa, enquanto que na quarta seção é abordada a análise dos resultados da pesquisa. Na sequência, na quinta seção, são apresentadas as considerações finais e, finalmente, na sexta seção, são relacionadas as referências que dão sustentação ao estudo.

\section{Embasamento Teórico: do Estado/Sociedade à Semiótica Informacional Contábil}

\subsection{A Triangulação entre Estado, Sociedade e Prestação de Contas}

As relações humanas criaram o Estado, agente regulador e soberano do convívio em sociedade. Ademais, é o Estado o instrumento do qual se utiliza o homem para realizar determinados fins, que levam ao bem comum em aderência ao princípio da continuidade do Estado.

Para alcançar seu objetivo, o Estado se estrutura politicamente na forma de governo e se organiza por meio do uso de suas funções públicas, entre elas a função administrativa do Estado, materializada por meio da Administração Pública.

Portanto, enquanto são políticas as funções de governo, são administrativas - como a própria expressão indica - as funções de Administração Pública, atividades das quais se utiliza o governo para cumprir seus objetivos que visam o interesse público e a execução das políticas públicas.

Dessa forma, é por intermédio da prestação de serviços públicos que o interesse público torna-se concreto e se faz representar. Nesse lume, Fuhrer e Fuhrer (2002, p. 52) definem o serviço público "como a atividade exercida pelo poder público, direta ou indiretamente, para realizar o que entende estar de acordo com os seus fins e suas atribuições".

Visto que todo o aparato estatal é financeiramente sustentado pela sociedade, faz-se necessário que o Estado não apenas realize a melhoria da qualidade de vida da população por meio do poder coercitivo de arrecadação de recursos públicos, mas, também, comprove, na elaboração da prestação de contas, a boa e regular utilização desses recursos aos detentores de seu capital, o cidadão. A esse respeito, Camargo (2010, p. 33) leciona que:

Sob qualquer prisma que se observe a relação entre o Estado e seus cidadãos, não é possível negligenciar quanto à prestação de contas ampla e transparente por parte dos agentes públicos, a fim de que se possibilite avaliação sobre o desempenho dos gestores públicos, norteando a ação estatal para o bem público, com eficácia e eficiência.

A prestação de contas dos agentes públicos permite proteger os interesses dos governados quanto aos recursos que financiam a atividade estatal, ao mesmo tempo em que responsabilizam seus executores. Neste matiz a International Federation of Accountants (Ifac) define a prestação de contas como sendo: 
[...] um processo por meio do qual as entidades do setor público, e os indivíduos dentro delas, são responsáveis por suas decisões e ações, incluindo a sua gestão de fundos públicos e todos os aspectos de desempenho, e se submetem ao escrutínio externo apropriado.

A mesma Ifac avalia que os esforços do Executivo para demonstrar a responsabilidade geralmente começam com um relatório financeiro adequado, o qual, no pleno cumprimento das normas de contabilidade, aumenta a responsabilidade financeira do gestor público, pois contribui para a confiabilidade, a consistência e a transparência das informações financeiras, elementos essenciais à boa e regular prestação de contas.

Assim, visto que, por força constitucional, em muitos momentos, o povo se faz representar no exercício de seu poder, a prestação de contas é condição inerente a todo aquele que exerce, em qualquer dos poderes, a expressão da vontade popular. Nessa linha, Young (2006, p. 151) defende que:

Na qualidade de um relacionamento prolongado entre os eleitores e seus agentes, a representação oscila entre momentos de autorização e de prestação de contas: é um ciclo de antecipação e retomada entre os eleitores e o representante, no qual seus discursos e ações devem carregar vestígios de um momento a outro.

Em consonância, no exercício de sua função pública, os agentes devem ter seus atos controlados quanto à legalidade e à finalidade.

Diante do colocado, torna-se importante conhecer quem fiscaliza e controla a aplicação do dinheiro público. Obtém-se resposta em Di Pietro (2001, p. 735) para quem: "no exercício de suas funções, a Administração Pública sujeita-se a controle por parte dos Poderes Legislativo e Judiciário, além de exercer, ela mesma, o controle sobre os próprios atos".

Ainda, visto que a obrigação legal do agente público em prestar contas tem origem na responsabilidade de delegação de poder emanado pela sociedade, tem-se como parte essencial do controle externo o controle social, como registrado pela própria Di Pietro (2001, p. 735) dando conta de que:

[...] embora o controle seja atribuição estatal, o administrado participa dele à medida que pode e deve provocar o procedimento de controle, não apenas na defesa de seus interesses individuais, mas também na proteção do interesse coletivo. A Constituição outorga ao particular determinados instrumentos de ação a serem utilizados com essa finalidade. É esse, provavelmente, o mais eficaz meio de controle da Administração Pública: o controle popular.

Com efeito, o agente público, ao realizar a gestão de recursos governamentais, assume a responsabilidade de prestar contas, atividade essa indissociável do controle. Neste lume, relacionam-se então de forma direta: a responsabilidade, a prestação de contas e o controle.

\subsection{Orçamento Público e Contabilidade Pública: Instrumentos de Controle Social}

A prestação de contas dos agentes públicos materializa-se por intermédio de seus principais e mais relevantes documentos de disclosure: as demonstrações contábeis, cujo conteúdo revela a execução do orçamento público, autorizado indiretamente pela sociedade, ou seja, por meio de seus representantes parlamentares, para a efetiva consecução das políticas públicas.

Acerca da participação e prática cidadã, Gallo (2003, p. 30) enfatiza que:

A ação democrática consiste em todos tomarem conta do processo decisório sobre aquilo que terá consequência na vida de toda a coletividade. Quem pode dizer o que é bom para todos? Aquele mesmo que irá provar - o próprio ser humano. Se não de forma direta, pelo menos por meio de seus representantes, desde que ele se mantenha ativo e vigilante, acompanhando o trabalho daqueles que elegeu. 
Essa vigilância ativa, por sua vez, é instrumentalizada pelos mecanismos de participação e controle popular. Nota-se então na visão de Bresser-Pereira (1998, p. 141) que:

Nas sociedades primitivas e no patrimonialismo, o espaço público e privado eram confundidos; no capitalismo liberal, o espaço privado se separa do público e ganha autonomia; no capitalismo burocrático, o espaço público volta a crescer, mas de forma estatal; no capitalismo do século vinte e um o espaço público voltará a crescer, mas agora no plano não estatal do controle social.

Diante das palavras de Bresser-Pereira (1998), confirma-se então que o controle social vai além da democracia representativa e está um passo adiante dos meios e ferramentas de participação social disponibilizados pela Constituição Federal. No mesmo raciocínio, Moroni (2005, p.40) esclarece que:

Quando falamos (sic.) em controle social, não nos referimos simplesmente a consulta do Estado pela sociedade civil. E também não se trata apenas da questão de acesso à informação. O controle social diz respeito ao direito que o cidadão tem de participar dos destinos da nação, além do já consolidado direito de representação.

Entretanto, para que seja efetivo, o controle social depende da efetividade da transparência da gestão pública, despertando a consciência e a motivação da sociedade para o exercício da cidadania.

Neste lume, Heald (2006) ensina que, para haver transparência efetiva, os usuários da informação divulgada pelo governo devem ser capazes de processá-las, compreendê-las e utilizá-las. O autor afirma, ainda, que, se a informação divulgada não for assimilada pelo cidadão, houve por parte do governo apenas a intenção de ser transparente.

Nesse sentido, Moroni (2005) destaca como elemento de relevância na questão do controle social o orçamento público. $\mathrm{O}$ autor ressalta que o orçamento perpassa os cinco eixos de sustentação do controle social, relacionados aos direitos de participação: (i) na elaboração, (ii) na deliberação, (iii) na implantação, (iv) no monitoramento e (v) na avaliação das políticas públicas.

O orçamento público é um instrumento de planejamento que busca responder às demandas da sociedade e se materializa por meio do processo orçamentário, procedimento que compreende um ciclo que "abrange a elaboração, a discussão, a aprovação do projeto de lei de orçamento, sua programação e execução, e o controle e avaliação da execução" (Rosa, 2011, p. 75).

É a contabilidade pública, no momento da execução do orçamento, que coloca em prática o que foi autorizado pela lei orçamentária e oportuniza, por meio da transparência e da evidenciação dos atos e fatos praticados pela Administração Pública, que se realizem as duas últimas etapas do processo orçamentário: o controle e a avaliação dos resultados obtidos pelas ações governamentais.

Em resumo, a contabilidade pública, ao processar a execução do orçamento e ao produzir informações econômicas, orçamentárias, financeiras e físicas acerca do patrimônio público, torna-se ferramenta de acompanhamento dos gastos do governo pela sociedade, por meio da devida prestação de contas dos agentes públicos, o que a coloca na condição de instrumento de controle social.

\subsection{A Contabilidade Pública como Ferramenta de Comunicação entre o Estado e a Sociedade}

Ao ilustrar a complexidade da relação entre o emissor e o receptor da informação contábil, McNellis (2013) pondera que um dos mais importantes - e mais difíceis - aspectos da composição da contabilidade é a definição do público-alvo, isso porque, a Ciência Contábil se utiliza de procedimentos e técnicas que têm implicações para o público em geral. Portanto, um estilo de escrita que só se encaixa dentro dos limites da contabilidade e da compreensão dos contabilistas terá pouco impacto sobre aqueles que veem o mundo de uma perspectiva diferente. Por outro lado, um estilo que carece de substância reduz a validade da escrita e, potencialmente, a credibilidade do seu autor. 
Tal complexidade também se configura na comunicação contábil entre Estado e sociedade. Desta forma, para que a contabilidade pública possa lograr com efetividade o objetivo de ser instrumento de avaliação de performance do gestor pelo cidadão, faz-se necessário que as demonstrações contábeis públicas sejam revestidas de linguagem compreensível, adaptando a comunicação contábil à compreensão de seu principal acionista, o cidadão senhorio da res-pública.

A compreensibilidade é requisito essencial à instrumentalização do controle social, consoante o conceito dado a essa expressão pela NBC T 16.1 (Conselho Federal de Contabilidade [CFC], 2008), que a define como "o compromisso fundado na ética profissional, que pressupõe o exercício cotidiano de fornecer informações que sejam compreensíveis e úteis aos cidadãos no desempenho de sua soberana atividade de controle do uso de recursos e patrimônio público pelos agentes públicos".

Oliveira (2005) ao estudar o nível de compreensibilidade do corpo docente do Departamento de Ciências Sociais Aplicadas da Universidade Estadual de Feira de Santana, sobre as demonstrações contábeis elaboradas pela administração públicas, concluiu que esse segmento de usuários teve dificuldade de compreensão das terminologias empregadas naquelas demonstrações e, em face desse resultado, os respondentes não teriam condições de analisar e interpretar os balaços públicos.

Miranda, Silva, Ribeiro e Silva (2008), ao investigarem o grau de compreensibilidade das informações apresentadas pelo Balanço Orçamentário, entre cidadãos com grau de escolaridade acima da média apresentada pela população brasileira, constataram que as informações produzidas pela contabilidade pública não são claras para a maioria dos cidadãos, independente do grau de escolaridade.

Nesse sentido, Dias (2009) pondera que diversos estudos comprovam a inconveniência de se utilizarem termos de maior complexidade em mensagens dirigidas a públicos não especializados. Para o autor esses usuários tendem a desprezar informações com expressões excessivamente técnicas; ao mesmo tempo, essas raramente conseguem despertar significados compatíveis com os pretendidos.

Para Oliveira (2005, p. 14), a perda da compreensibilidade das terminologias contábeis são resultados da não observância aos fatores que determinam a fidelidade do processo de comunicação, que está condicionado: "ao exame dos objetivos do emissor e do receptor das mensagens, suas habilidades comunicativas, níveis de conhecimento sobre a matéria veiculada, contexto sociocultural em que se encontra envolvido, adequação da mensagem, compatibilidade do canal".

A respeito da linguagem e do processo de comunicação contábil, Dias (2009 e Dias e Nakagawa (2001) valem-se em seus estudos da Teoria da Comunicação, considerando que, para esta teoria, os significados não são propriedades das palavras, mas dos indivíduos.

A transposição dos elementos estruturais da Teoria da Comunicação para o processo de comunicação contábil pode ser representada da seguinte forma: (i) emissor: produtores da informação contábil; (ii) receptor: usuário da informação; (iii) mensagem: conjunto de informações de natureza econômica e financeira, apuradas por meio de sistema articulado de dados e de técnicas de acumulação, promovidos por normas e princípios contábeis; (iv) código: terminologia dos relatórios contábeis; e (v) canal: suporte físico das informações, como os relatórios contábeis (Vasile, Aristita, Cristina \& Mihaela, 2009).

Dentro desse processo de comunicação, o enfoque é a relação entre o emissor e o receptor da informação, minimizando possíveis ruídos que interfiram no entendimento da mensagem. Desta forma, Platt, Cruz, Ensslin e Ensllin (2007) entendem que, para se alcançar eficácia na participação popular nas questões relativas ao exercício da atividade pública, faz-se necessária a preocupação com a compreensibilidade das informações divulgadas pelo Estado, buscando-se linguagem adequada, simples e acessível, também ao cidadão comum.

Para Batista (2010) o cidadão necessita entender as dinâmicas da relação Estado-sociedade as quais se revelam na compreensão e consequente apropriação da informação pública.

Nessa linha, Barreto (1994, p. 3) leciona que "a informação, quando adequadamente assimilada, produz conhecimento, modifica o estoque mental de informações do indivíduo e traz benefícios ao seu desenvolvimento e ao desenvolvimento da sociedade em que ele vive". 
Entretanto, no Brasil, embora a Constituição Federal de 1988 tenha se tornado conhecida como a "constituição cidadã", não foram, constitucionalmente, previstas diretrizes que visem à garantia da educação como ferramenta de desenvolvimento de uma consciência cidadã (Batista, 2010).

Com efeito, o desafio é adequar a mensagem contábil, seu conteúdo e canal de comunicação às características do usuário. Aproximar-se dessa tarefa é o que ambiciona este trabalho, por meio das hipóteses levantadas e da metodologia empregada e detalhada no tópico seguinte.

\section{Metodologia}

Considerando o objetivo geral desta investigação, a população escolhida para objeto de estudo se faz representar pelos presidentes das entidades comunitárias da cidade de Curitiba, que totalizavam em agosto de 2013, de acordo com a Federação Comunitária das Associações de Moradores de Curitiba e Região Metropolitana (Femoclam), cerca de 1.150 entidades.

Justifica-se a escolha deste universo de pesquisa por tratar-se de respondentes que possuem, em tese, as características presentes no cidadão médio, definido por Reis $(2007$, p. 1) como "o brasileiro letrado, cada vez mais desejoso de entender o enigma representado pelo seu próprio país, que avança em tantos aspectos, sem sair do lugar em outros".

Argumenta-se, ainda, que as associações de moradores possuem, intrinsecamente, a natureza de diligenciar e contribuir para a formação e o desenvolvimento da vida comunitária, o que ocorre também pela promoção do esclarecimento e da disseminação da informação contextualizada que confira qualidade ao controle social. Além disso, atuam na defesa dos interesses dos cidadãos perante as diversas organizações públicas, representando aproximadamente $30 \%$ das entidades do terceiro setor que atuam no desenvolvimento e defesa de direitos no Brasil, conforme dados do Instituto Brasileiro de Geografia e Estatística (IBGE), (2010).

Nesse contexto, as associações de moradores contribuem para a promoção do esclarecimento e da disseminação da informação contextualizada que confira qualidade ao controle social aplicável sobre a efetivação do Estado por meio da implementação de políticas públicas demandadas pelos cidadãos integrantes desses grupos civilmente organizados.

Em relação à amostra, ela foi escolhida por conveniência e acesso (Yin, 2010), considerando: i) a aplicabilidade operacional do questionário e ii) a área de abrangência da gestão dos coordenadores das regionais das associações de moradores selecionadas.

Colocando em prática para este estudo a fórmula elaborada por Lax e Phillips (2009) e considerando a população de 1.150 entidades, chegou-se ao tamanho mínimo da amostra de 92 associações de moradores, conforme memória de cálculo (Equação 1), para um erro amostral $\left(\mathrm{n}_{\mathrm{o}}\right)$ tolerável de $10 \%(0,10)$.

$$
\begin{gathered}
n=\left[\left(N \times n_{o}\right) /\left(N+n_{o}\right)\right] \\
n=[(1150 \times 100) /(1150+100)]=92
\end{gathered}
$$

No que concerne à elaboração do questionário, este possui respostas fechadas, distribuídas em tipos de múltipla escolha, escalonadas na forma nominal ou ordinal, essa última baseada no modelo de escalonamento de Likert. Desta forma, as assertivas foram amparadas por uma escala de 1 a 4 , na qual os respondentes apontaram seu grau de conhecimento sobre a terminologia apresentada (alto conhecimento, razoável, pouco ou nenhum conhecimento).

Considerado o problema de pesquisa e a população escolhida para aplicação do questionário, a intenção na construção do instrumento foi torná-lo de fácil compreensão e aplicação. Assim, o instrumento foi encaminhado aos presidentes das associações de moradores pertencentes às regionais dos bairros de Santa Felicidade, Cajuru, Bairro Novo, Boa Vista e Pinheirinho e para três coordenadores internos da Femoclam, todos escolhidos de forma aleatória, a fim de ser aplicado o pré-teste. 
De acordo com Gil (2002, pp.119-120), o pré-teste «está centrado na avaliação dos instrumentos enquanto tais, visando garantir que meçam exatamente o que pretendem medir». Quanto aos indivíduos selecionados para o pré-teste, o autor afirma que "é necessário que esses indivíduos sejam típicos em relação ao universo pesquisado".

Ainda, levando-se em conta as características da população da amostra, decidiu-se por realizar a aplicação da pesquisa em papel. Assim, o banco de dados com as variáveis estudadas foi alimentado de forma mecânica.

No que diz respeito à aplicação do instrumento de coleta, esta se deu de forma pessoal e direta aos respondentes em seis oportunidades nas em reuniões da Femoclam, ocorridas nos meses de agosto e setembro de 2013. Nessas reuniões, promovidas nas coordenações regionais das associações de moradores, foram explicadas aos presentes, de forma oral, a natureza da pesquisa, sua importância e necessidade de resposta e, em seguida, distribuídos os questionários, sendo esses devolvidos até o final de cada reunião.

No total foram distribuídos 116 questionários, dos quais foram respondidos 107. Desse montante, 4 foram considerados inválidos, por apresentarem respostas incompletas. Totalizando, ao final, 103 questionários válidos.

Em relação à mensuração dos dados, esta foi realizada por meio de variáveis ordinais e nominais. Nas variáveis nominais, os dados podem ser colocados em categorias e contados somente com relação à frequência com que ocorrem, não contendo nenhuma ordenação ou avaliação. Já as variáveis ordinais vão um pouco além das variáveis nominais e podem prover informações a respeito da ordenação das categorias (Rea \& Parker, 2002).

Por fim, para se estudar a distribuição das variáveis, empregaram-se as análises uni e bivariada. A análise univariada envolve a observação de uma variável separadamente, enquanto que, na bivariada, são testadas hipóteses que comparam as características de duas ou mais variáveis com o objetivo de verificar a inter-relação entre elas (Hair, Wolfinbarger, Ortinau \& Bush, 2010).

Assim, a fim de testar as hipóteses colocadas, o tratamento estatístico dos dados coletados via pesquisa de campo foi interpretado com auxílio do teste $\chi^{2}$.

A realização do teste $\chi^{2}$ neste trabalho se deu por meio da aplicação do software estatístico "R", programa gratuito, de código aberto e livremente distribuído aos usuários interessados pela Universidade Federal do Paraná (UFPR).

\section{Análise dos Resultados da Pesquisa}

Organizados e resumidos os dados levantados na pesquisa de campo, procede-se então à análise exploratória a fim de dar-lhes significados e obter informações que permitam responder à questão norteadora deste trabalho, a partir do seu objetivo geral.

Neste matiz realiza-se o exame dos dados sob dois aspectos: no primeiro deles, visa caracterizar o perfil sociodemográfico da população pesquisada; e, no segundo, procede-se à análise descritiva de cada variável observada, e as inferências sobre as características da população que atendem ao objetivo proposto para a presente investigação.

Esta primeira análise foi amparada pela construção da distribuição de frequência das variáveis em estudo. Em uma segunda análise, aplicou-se o teste $\chi^{2}$ à amostra obtida, com o intuito de verificar a relação entre as variáveis consideradas importantes para a hipótese que se pretende testar. 


\subsection{Caracterização do Perfil Sociodemográfico da Amostra}

O perfil sociodemográfico permite conhecer os atributos individuais da população em estudo. Para esta investigação, considerou-se importante conhecer o gênero, o nível de escolaridade, a faixa etária e a ocupação. Esse conjunto de informações pode ser observado para a amostra obtida nesta pesquisa por meio das Tabelas 1,2 e 3.

Tabela 1

Distribuição por Gênero

\begin{tabular}{lcc}
\hline Gênero & Frequência & $\%$ \\
\hline Feminino & 35 & 34 \\
\hline Masculino & 68 & 66 \\
\hline Total & 103 & 100 \\
\hline
\end{tabular}

Fonte: pesquisa de campo. A soma das parcelas difere do total devido a critérios de arredondamento.

Tabela 2

Distribuição por Nível de Escolaridade

\begin{tabular}{lcc}
\hline Nível de Escolaridade & Frequência & $\%$ \\
\hline Ensino Fundamental Incompleto & 16 & 16 \\
\hline Ensino Fundamental Completo & 11 & 11 \\
\hline Ensino Médio Incompleto & 6 & 6 \\
\hline Ensino Médio Completo & 39 & 38 \\
\hline Superior Incompleto & 11 & 11 \\
\hline Superior Completo & 10 & 10 \\
\hline Pós-Graduação & 10 & 10 \\
\hline Total & 103 & 100 \\
\hline
\end{tabular}

Fonte: pesquisa de campo. A soma das parcelas difere do total devido a critérios de arredondamento.

Tabela 3

Distribuição por Faixa Etária

\begin{tabular}{lcc}
\hline Faixa Etária & Frequência & $\%$ \\
\hline 20 a 30 anos & 10 & 10 \\
\hline 31 a 40 anos & 15 & 15 \\
\hline 41 a 50 anos & 29 & 28 \\
\hline 51 a 60 anos & 38 & 37 \\
\hline 61 a 70 anos & 9 & 9 \\
\hline 71 anos ou mais & 2 & 2 \\
\hline Total & 103 & 100 \\
\hline
\end{tabular}

Fonte: pesquisa de campo. A soma das parcelas difere do total devido a critérios de arredondamento.

Em relação às características sociodemográficas apresentadas, destaca-se a menor presença feminina nas lideranças comunitárias, como indica a Tabela 1, visto que as mulheres representam apenas $34 \%$ dessa categoria, ainda que sua participação demográfica na cidade de Curitiba aproxime-se dos 57\% (IBGE, 2010).

Em relação à faixa etária, a Tabela 3 demonstra que há uma preponderância de líderes comunitários entre a chamada idade madura e a idade média ( 40 a 60 anos). 
Outra observação diz respeito à heterogeneidade dos graus de instrução da amostra (Tabela 2), com destaque para o percentual de pessoas com nível superior completo, de $20 \%$, índice relativamente superior ao encontrado no país para pessoas com mais de 25 anos de idade, de 11,03\% de pessoas nesta faixa de escolaridade (IBGE, 2010).

\subsection{Análise Descritiva}

Com o objetivo de obter uma visão global das variáveis medidas e a fim de evidenciar resultados relevantes sobre a população pesquisada, foi realizada a análise descritiva de cada variável observada na pesquisa de campo, a partir dos seus valores sintetizados.

Assim, sobre a utilização do dinheiro público, verifica-se, pela frequência auferida na Tabela 4, que a maioria (60\%) afirma que nunca, ou raramente, busca informações sobre o uso do dinheiro público.

Tabela 4

Distribuição por Frequência na Procura de Informações sobre a Utilização do Dinheiro Público

\begin{tabular}{lcc}
\hline Frequência & Frequência & $\%$ \\
\hline Sempre & 19 & 18 \\
\hline Às vezes & 22 & 21 \\
\hline Raramente & 34 & 33 \\
\hline Nunca & 28 & 27 \\
\hline Total & 103 & 100 \\
\hline
\end{tabular}

Fonte: pesquisa de campo. A soma das parcelas difere do total devido a critérios de arredondamento.

Entre os que buscam informações sobre a utilização do dinheiro público, os Tribunais de Contas representam a fonte com menor total de indicações, com 18 respostas, enquanto as audiências públicas obtiveram o maior número de indicações (33), como pode ser observado na Tabela 5.

Tabela 5

Distribuição por Fontes de Informações Consultadas para Acesso à Prestação de Contas dos Agentes Públicos

\begin{tabular}{lcc}
\hline Fonte & Frequência & $\%$ \\
\hline Audiências públicas & 34 & 33 \\
\hline Câmaras municipais & 22 & 21 \\
\hline Páginas oficinas na internet & 28 & 27 \\
\hline Tribunais de contas & 19 & 18 \\
\hline Total & 103 & 100 \\
\hline
\end{tabular}

Fonte: pesquisa de campo. A soma das parcelas difere do total devido a critérios de arredondamento.

Neste ponto, vale destacar que não surpreende a audiência pública ser a maior fonte de consulta indicada, visto ser este o maior mecanismo de participação direta dessa população nas discussões relativas às decisões do governo e à elaboração de políticas públicas, em especial quanto às realizadas pelo Poder Público municipal.

Como é possível observar pela Tabela 6, entre os 103 entrevistados, 73 declararam ter grande interesse sobre o conteúdo das prestações de contas, enquanto apenas um afirmou não ter qualquer interesse nesta informação. 
Tabela 6

Distribuição por Grau de Interesse nas Prestações de Contas dos Agentes Públicos

\begin{tabular}{lcc}
\hline Grau de Interesse & Frequência & $\%$ \\
\hline Grande & 73 & 71 \\
\hline Médio & 20 & 19 \\
\hline Pouco & 9 & 9 \\
\hline Nenhum & 1 & 1 \\
\hline Total & 103 & 100 \\
\hline
\end{tabular}

Nota. Fonte: Pesquisa de Campo. A soma das parcelas difere do total devido a critérios de arredondamento.

Dos dados encontrados e expostos pode-se inferir que, embora $71 \%$ dos respondentes possuam grande interesse em conhecer o conteúdo da prestação de contas, apenas 39\% procuram se informar, sempre e às vezes (Tabela 4), sobre a utilização dos recursos públicos.

A aparente contradição pode ser explicada, em parte, por dois pontos preponderantes durante a aplicação dos questionários e objetos de apontamentos nas reuniões que dizem respeito: i) à falta de conhecimento dos respondentes quanto às formas de acesso às prestações de contas, e ii) ao desconhecimento do conteúdo que pode ser extraído das informações contábeis públicas.

Outra observação que pode esclarecer a contraposição dos dados encontrados relaciona-se ao pouco ou nenhum conhecimento declarado pelos respondentes sobre a informação contábil pública, no total de $57 \%$ da amostra, como indica a Tabela 7.

Tabela 7

Distribuição por Grau de Conhecimento quanto à Informação Contábil Pública

\begin{tabular}{lcc}
\hline Grau de Conhecimento & Frequência & $\%$ \\
\hline Alto & 6 & 6 \\
\hline Médio & 38 & 37 \\
\hline Pouco & 35 & 34 \\
\hline Nenhum & 24 & 23 \\
\hline Total & 103 & 100 \\
\hline
\end{tabular}

Fonte: pesquisa de campo.

A essa declaração agrega-se a dificuldade de entendimento da terminologia empregada pelas demonstrações contábeis, considerando que apenas 34\% dos respondentes consideram o Balanço Orçamentário da Prefeitura de Curitiba compreensível por pessoas sem formação na área contábil (dado revelado pela Tabela 8).

Tabela 8

Distribuição por Avaliação quanto à Compreensão da Linguagem do Balanço Orçamentário da Cidade de Curitiba do ano de 2012

\begin{tabular}{lcc}
\hline Avaliação & Frequência & $\%$ \\
\hline Compreensível & 35 & 34 \\
\hline De razoável compreensão por não contabilistas & 33 & 32 \\
\hline Não compreensível por não contabilistas & 35 & 34 \\
\hline Total & 103 & 100 \\
\hline
\end{tabular}

Fonte: pesquisa de campo. 
Como se pode observar, esses achados se alinham aos resultados colhidos nas pesquisas de Oliveira (2005) e Miranda et al. (2008), no que se refere à dificuldade de entendimento do cidadão sobre a terminologia contábil empregada nos demonstrativos produzidos pela contabilidade governamental. Tal dificuldade não apenas induz o usuário a ignorar a informação, como é, por si só, fator desestimulador de um comportamento assíduo de busca pela informação, independentemente do contexto de vida do cidadão.

Dando continuidade ao objetivo de conhecer o grau de entendimento da população quanto à informação contábil pública, optou-se neste trabalho por apresentar à população estudada alguns termos básicos da contabilidade pública para avaliação.

Esses termos foram escolhidos por representarem termos técnicos comumente empregados em meios de comunicação de massa, portanto, de maior perspectiva de assimilação pela população em geral. Ao mesmo tempo, demonstram, de forma objetiva, o comportamento do orçamento público, por meio da arrecadação (receita), do desembolso (despesa) e da gestão governamental sobre os recursos públicos, expressa pelos seus resultados possíveis (superávit e déficit).

Tabela 9

Distribuição por Grau de Conhecimento quanto aos Termos Superávit e Déficit

\begin{tabular}{|c|c|c|c|c|c|c|c|c|c|c|}
\hline \multirow{3}{*}{ Termos } & \multicolumn{10}{|c|}{ Grau de Conhecimento } \\
\hline & \multicolumn{2}{|c|}{ Alto } & \multicolumn{2}{|c|}{ Razoável } & \multicolumn{2}{|c|}{ Pouco } & \multicolumn{2}{|c|}{ Nenhum } & \multicolumn{2}{|c|}{ Total } \\
\hline & f. & $\%$ & f. & $\%$ & f. & $\%$ & f. & $\%$ & f. & $\%$ \\
\hline Superávit & 6 & 6 & 32 & 31 & 34 & 33 & 31 & 30 & 103 & 100 \\
\hline Déficit & 6 & 6 & 34 & 33 & 42 & 41 & 21 & 21 & 103 & 100 \\
\hline
\end{tabular}

Fonte: pesquisa de campo.

Pode-se verificar, pela Tabela 9, que 31\% dos respondentes afirmam não possuir conhecimento sobre o termo superávit, enquanto o termo déficit teve $21 \%$ de respostas que declaram o seu desconhecimento. Não obstante, $37 \%$ dos respondentes alegam ter razoável/alto conhecimento acercado do termo.

O menor índice de desconhecimento para o termo déficit em relação ao superávit pode ser justificado pela trajetória das contas públicas no Brasil.

O déficit público se tornou uma questão central no debate econômico no país, em especial, como causa explicativa do processo inflacionário, quando o governo gasta mais do que arrecada. Consequentemente, esse termo acaba por sobrevir com mais frequência no noticiário nacional, tornando-se, naturalmente, de maior conhecimento da população em geral.

Em comparação com os valores encontrados na Tabela 9, pode-se inferir que há uma compreensão moderadamente satisfatória dos elementos "receita pública" e "despesa pública" por parte dos respondentes, pois $15 \%$ e $17 \%$, respectivamente, declararam não possuir nenhum conhecimento acerca desses termos, conforme se observa nos dados explicitados pela Tabela 10.

Tabela 10

Distribuição por Grau de Conhecimento quanto aos Termos Receita Pública e Despesa Pública

\begin{tabular}{|c|c|c|c|c|c|c|c|c|c|c|}
\hline \multirow{3}{*}{ Termos } & \multicolumn{10}{|c|}{ Grau de Conhecimento } \\
\hline & \multicolumn{2}{|c|}{ Alto } & \multicolumn{2}{|c|}{ Razoável } & \multicolumn{2}{|c|}{ Pouco } & \multicolumn{2}{|c|}{ Nenhum } & \multicolumn{2}{|c|}{ Total } \\
\hline & f. & $\%$ & f. & $\%$ & f. & $\%$ & f. & $\%$ & f. & $\%$ \\
\hline Receita Pública & 7 & 7 & 49 & 48 & 32 & 31 & 15 & 15 & 103 & 100 \\
\hline Despesa Pública & 4 & 4 & 49 & 48 & 33 & 32 & 17 & 17 & 103 & 100 \\
\hline
\end{tabular}

Fonte: pesquisa de campo. A soma das parcelas difere do total devido a critérios de arredondamento. 
Esses percentuais, além de revelarem o grau de conhecimento da população pesquisada sobre a terminologia básica da contabilidade pública, amparam a percepção de que há aprendizado para o cidadão quando este toma parte na vida pública. Isso porque há grande participação dos respondentes nas audiências públicas, em particular quanto às discussões relacionadas à Lei Orçamentária Anual (LOA) quando os termos "despesa pública" e "receita pública" são mais comumente utilizados e discutidos.

Com respeito ao tipo de apresentação que melhoraria o entendimento sobre as informações contábeis públicas, os dados da Tabela 11 destacam a preferência pela linguagem acessível (51\%), corroborando o que foi destacado pela teoria da Comunicação neste trabalho, uma vez que indica a necessidade de adaptação dos códigos da mensagem da contabilidade pública ao entendimento de seu receptor, no caso, o cidadão médio.

Tabela 11

Distribuição por Tipo de Apresentação de Preferência que Melhoria o Entendimento sobre as Informações Contábeis Públicas

\begin{tabular}{lcc}
\hline Grau de Utilidade & Frequência & $\%$ \\
\hline Linguagem acessível & 53 & 51 \\
\hline Cartilha & 21 & 20 \\
\hline Vinculação com eventos relacionados ao cotidiano das pessoas & 10 & 10 \\
\hline Demonstrativo resumido & 9 & 9 \\
\hline Tabelas & 6 & 6 \\
\hline Representação gráfica & 4 & 4 \\
\hline Total & 103 & 100 \\
\hline
\end{tabular}

Fonte: pesquisa de campo.

Em relação à cartilha, credita-se sua preferência em segundo lugar, (20\%), por ser essa um meio contumaz de capacitação das lideranças comunitárias, além de veículo de comunicação pedagógica na disseminação de informação dos órgãos do governo para a sociedade em geral.

Assim, mais uma vez, se observa a aderência do resultado à teoria da Comunicação, agora quanto ao canal utilizado para transmissão da mensagem ao destinatário, ou seja, revela a necessidade de adequação da exposição dos relatórios contábeis em um meio de comunicação a que o indivíduo já esteja familiarizado e que apresente não apenas o resultado, mas a análise e interpretação desse resultado, de forma didática, mediada por linguagem verbal acessível à compreensão do cidadão.

No intuito de evidenciar outras informações relevantes a partir do grau de associação entre as variáveis de interesse, e com o intento de testar a hipótese colocada neste estudo, foi aplicado o teste $\chi^{2}$, em que o grau de associação entre duas ou mais variáveis analisadas é medido pelo p-value abaixo de 0,05.

Deste modo, para verificar se existe diferença entre as frequências observadas para o nível de escolaridade e o grau de conhecimento acerca da informação contábil pública, tem-se a distribuição apresentada na Tabela 12.

Tabela 12

Distribuição do nível de escolaridade por grau de conhecimento sobre a informação contábil pública

\begin{tabular}{|c|c|c|c|c|}
\hline \multirow[t]{2}{*}{ Nível de Escolaridade } & \multicolumn{3}{|c|}{$\begin{array}{l}\text { Grau de Conhecimento sobre a } \\
\text { Informação Contábil Pública }\end{array}$} & \multirow[t]{2}{*}{ Total } \\
\hline & Nenhum & Pouco & Razoável/Alto & \\
\hline Ensino fundamental de $1 .^{\mathrm{a}}$ a $8 .^{\mathrm{a}}$ incompleto e completo & 14 & 8 & 5 & 27 \\
\hline Ensino médio incompleto e completo & 8 & 18 & 19 & 45 \\
\hline Ensino superior incompleto, completo e pós-graduação & 2 & 9 & 20 & 31 \\
\hline Total & 24 & 35 & 44 & 103 \\
\hline
\end{tabular}

Nota: $X$-squared $=21.8175, p$-value $=0.0002179$

Fonte: pesquisa de campo. 
Neste caso, para um p-value de 0.0002179 , é possível afirmar que há relação entre o nível de escolaridade e o grau de conhecimento sobre a informação contábil pública, indicando que quanto maior o nível de escolaridade, maior o grau de conhecimento apresentado.

Essa afirmação pode ser estendida para os valores obtidos na aplicação do teste para as variáveis, grau de conhecimento dos termos superávit e déficit e o nível de escolaridade dos respondentes, Tabelas 13 e 14 , p-valores de $=8.05$ e- 06 e 0.006949 , respectivamente.

Os achados evidenciados na Tabela 12, 13 e 14 corroboram os estudos de Weibenberger e Holthoff (2013) os quais apontam que o nível de conhecimento formal de uma pessoa parece ser um determinante das dimensões conotativas que ela atribui aos termos contábeis. A conotação é o que a significação tem de particular para um indivíduo ou para um dado grupo dentro de uma comunidade (Dubois, Gicamo, Guespin, Marcellessi, Marcellessi \& Mevel, 2022, p. 142).

Tabela 13

Distribuição do Nível de Escolaridade por Grau de Conhecimento sobre Termos Básicos da Contabilidade Pública - Superávit

\begin{tabular}{|c|c|c|c|c|}
\hline \multirow[t]{2}{*}{ Nível de Escolaridade } & \multicolumn{3}{|c|}{$\begin{array}{c}\text { Grau de Conhecimento sobre o } \\
\text { Termo Superávit }\end{array}$} & \multirow[t]{2}{*}{ Total } \\
\hline & Nenhum & Pouco & Razoável/Alto & \\
\hline Ensino fundamental de $1^{\mathrm{a}}$ a $8^{\mathrm{a}}$ incompleto e completo & 17 & 5 & 5 & 27 \\
\hline Ensino médio incompleto e completo & 12 & 20 & 13 & 45 \\
\hline Ensino superior incompleto, completo e pós-graduação & 2 & 9 & 20 & 31 \\
\hline Total & 31 & 34 & 38 & 103 \\
\hline
\end{tabular}

Nota: $X$-squared $=28.9374, p$-value $=8.05 \mathrm{e}-06$.

Fonte: pesquisa de campo.

Tabela 14

Distribuição do Nível de Escolaridade por Grau de Conhecimento sobre Termos Básicos da Contabilidade Pública - Déficit

\begin{tabular}{|c|c|c|c|c|}
\hline \multirow[t]{2}{*}{ Nível de Escolaridade } & \multicolumn{3}{|c|}{$\begin{array}{c}\text { Grau de Conhecimento sobre o } \\
\text { Termo Déficit }\end{array}$} & \multirow[t]{2}{*}{ Total } \\
\hline & Nenhum & Pouco & Razoável/Alto & \\
\hline Ensino fundamental de $1^{\mathrm{a}}$ a $8^{\mathrm{a}}$ incompleto e completo & 11 & 10 & 6 & 27 \\
\hline Ensino médio incompleto e completo & 7 & 22 & 16 & 45 \\
\hline Ensino superior incompleto, completo e pós-graduação & 3 & 10 & 18 & 31 \\
\hline Total & 21 & 42 & 40 & 103 \\
\hline
\end{tabular}

Nota: $X$-squared $=14.1109, p$-value $=0.006949$.

Fonte: pesquisa de campo

Essas inferências permitem, ainda, testar a hipótese formulada: a educação formal tem influência na compreensibilidade da informação contábil pública compartilhada pelo Estado. Restando, desta forma, estabelecida a correlação entre as variáveis: "nível de escolaridade" e "grau de conhecimento sobre a informação contábil pública”.

Nesta mesma linha, Abrajano (2005) afirma que, embora a educação e o engajamento não sejam a mesma coisa, ainda assim estão fortemente correlacionados, e a educação representa um dos principais meios pelo qual o cidadão aprende a receber e a processar informações sobre o contexto político. 
Diante das exposições colocadas, entende-se que a abordagem permite inferir que há dificuldade de entendimento da terminologia contábil pública pelos respondentes, considerando o pouco ou nenhum conhecimento declarado pela maioria dos entrevistados. Essa inferência se apoia, também, na parcela significativa dos pesquisados que entendem que a demonstração contábil não é totalmente compreensível por pessoas que não possuam formação na área contábil.

Pode-se, ainda, argumentar que há uma maior probabilidade de o cidadão ser relativamente mais informado quando há a sua efetiva participação na vida pública, pelos meios colocados à disposição da sociedade pelo próprio Estado, como ocorre com as audiências públicas.

Pondera-se, também, que a compreensão do cidadão médio sobre a prestação de contas dos agentes públicos, a partir das demonstrações contábeis públicas, pode ser ampliada com a adequação da terminologia dos relatórios contábeis à capacidade de compreensão do cidadão.

Por fim, fica demonstrada a necessidade de melhoria do desenvolvimento social do país, por meio da efetividade da política pública essencial representada pela educação, a qual é, constitucionalmente, positivada como direito fundamental dos cidadãos, isso visando a um melhor entendimento da população sobre a informação pública compartilhada pelo Estado.

\section{Considerações Finais}

O presente estudo teve origem no interesse de se investigar como um dos pressupostos da nova contabilidade pública brasileira, de melhoria na transparência e evidenciação das informações governamentais, pode influenciar na função social da contabilidade aplicada ao setor público, que é ser ferramenta de controle social sobre os atos da administração pública, do Estado e do Governo.

Considerando que a transparência pressupõe não apenas a evidenciação da informação, mas também a sua compreensibilidade, entendeu-se que o primeiro passo deveria ser conhecer o grau de entendimento do cidadão médio sobre a informação contábil pública, representado nesta pesquisa pelos líderes comunitários da cidade de Curitiba.

A investigação se utilizou do questionário, procedimento escolhido como técnica e instrumento de coleta de dados em campo, o qual foi aplicado nas reuniões mensais das regionais de associações de moradores selecionadas.

Identificou-se, então, que $57 \%$ dos pesquisados possuem pouco ou nenhum conhecimento quanto à informação contábil pública. Enquanto outros $30 \%$ indicam não possuir nenhum conhecimento quanto ao termo superávit, e outros $21 \%$ desconhecem o significado do termo "déficit", itens determinantes dos resultados da gestão do administrador público sobre os recursos públicos.

É importante evidenciar, também, que, embora $60 \%$ dos respondentes não procurem se informar sobre a utilização do dinheiro público, $90 \%$ consideram muito ou médio o interesse em conhecer o conteúdo da prestação de contas. Infere-se da observação, durante as reuniões das associações, que muitas vezes não o fazem por falta da informação básica de onde encontrar esta informação ou por desconhecer o conteúdo da prestação de contas e seu significado.

Assim, se é importante dar publicidade à gestão pública, é da mesma forma essencial compartilhá-la, de modo a permitir que o cidadão se aproprie desse conhecimento (transparência), o que de fato interessa à materialização do controle social.

Resta concluído, à luz dos elementos obtidos em campo, que os respondentes, em sua maioria, não conseguem interpretar adequadamente as informações possibilitadas pelos dados disponibilizados nos relatórios contábeis públicos, peças que compõem a prestação de contas dos agentes públicos, instrumento que tem como função primordial comunicar a ação pública e gerar confiança social.

A discussão apresentada torna-se relevante perante a ampla gama de interessados nas informações contábeis públicas, que possuem características distintas em relação aos usuários tradicionais da contabilidade. 
Além disso, a norma geral de que "relatórios contábil-financeiros são elaborados para usuários que têm conhecimento razoável de negócios e de atividades econômicas e que revisem e analisem a informação diligentemente" (Resolução n. ${ }^{\circ} 1.374$, CFC, 2011) deve ser aplicada com moderação quando se trata do cidadão, usuário que se orienta pelo controle social e principal acionista do Estado, e a quem é devida a obrigatória prestação de contas.

Desta forma, para responder à questão da pesquisa de como melhorar a compreensibilidade, pelo cidadão, sobre a informação contida nas demonstrações contábeis públicas, pondera-se, a partir dos diagnósticos realizados, que as restrições na comunicação contábil podem ser reduzidas se essa for exposta em linguagem de fácil compreensão, mediada por formas de evidenciação complementares que contemplem linguagem verbal e não verbal e que apresente não apenas os resultados, mas a análise e interpretação desses resultados.

Destarte, espera-se que as variáveis observadas possam ser resumidas em um produto a ser utilizado pela sociedade, na forma de um sistema de informações flexível que permita a construção de pesquisas a partir de dados extraídos da análise e interpretação das demonstrações contábeis públicas, de sorte que os resultados sejam apresentados, também, na forma de gráficos, figuras e outras formas de comunicação não verbal. Esse sistema estaria em ambiente web, com acesso pelas páginas de transparências públicas dos órgãos e entidades governamentais.

Observa-se, por fim, a necessidade de desenvolvimento da política pública essencial representada pela educação visando à efetiva apropriação social da informação contábil pública, considerando que os resultados validam a hipótese colocada. Desta forma, a educação formal por ser um determinante no desenvolvimento da capacidade intelectual dos indivíduos, tende a influenciar no maior nível de entendimento da informação compartilhada pelo Estado.

Assim, considera-se que a principal contribuição deste trabalho é colocar em discussão a necessidade de uma proposta de instrumento de controle social que facilite o entendimento da população sobre as demonstrações contábeis públicas. Espera-se, ainda, que os resultados encontrados em decorrência da pesquisa possam servir de referência para outros estudos que possuam como tema a instrumentalização do controle social por meio das informações contábeis públicas.

De modo geral, verifica-se que se faz necessário o compartilhamento, pelos órgãos governamentais, de informações publicadas de forma compreensível, a fim de permitir a interação do Poder Público com a sociedade e a construção do conhecimento do cidadão sobre a lógica que rege o processo de prestação de contas, facilitando, desta forma, a apropriação social da informação pública.

\section{Referências}

Abrajano, M. A. (2005). Who evaluates a presidential candidate by using non-policy campaign messages? Political Research Quarterly, 58(1), pp.55-67. doi 10.1177/106591290505800105

Barreto, A. A. (1994). A questão da informação. São Paulo em Perspectiva, 8(4), pp. 3-8. doi.org/10.1590/ S0102-88392002000300012

Batista, C. L. (2010). Informação pública: entre o acesso e a apropriação social. Dissertação de Mestrado. Universidade de São Paulo, São Paulo, SP, Brasil. Recuperado de http://www.teses.usp.br/teses/disponiveis/27/27151/tde-05112010-110124/pt-br.php doi.org/10.1590/S0103-378620100000300003

Bresser-Pereira, L. C. (1998). Uma reforma gerencial da administração pública no Brasil. Revista do Serviço Público, 49(1), pp. 5-42. doi.org/10.1590/\$0034-75902010000100009

Camargo, G. B. (2010). Governança republicana como vetor para a interpretação das normas de direito financeiro. Tese de Doutorado. Faculdade de Direito da Universidade de São Paulo, São Paulo, SP, Brasil. Recuperado de http://www.teses.usp.br/teses/disponiveis/2/2133/tde-19112010-080857/pt-br.php. 
Di Pietro, M. S. (2001). Direito administrativo. (13a ed.). São Paulo: Atlas

Dias, J. M., Filho \& Nakagawa, M. (2001). Análise do processo de comunicação contábil: uma contribuição para a solução de problemas semânticos, utilizando conceitos da teoria da comunicação. Revista Contabilidade \& Finanças, 12(26), pp. 42-57. Recuperado de http://www.scielo.br/pdf/rcf/ v12n26/v12n26a03.pdf.

Dias, J. M., Filho (2009). A contabilidade e a ordem social. Revista de Contabilidade da Ufba, 3(3), pp. 3-4.

Dubois, J., Giacomo, M., Guespin, L., Marcellesi, C., Marcellesi, J.-B. \& Mevel, J.-P. (2011). Dicionário de Lingüística. São Paulo: Ed. Pensamentos Cultrix Ltda.

Fuhrer, M. C. A. \& Fuhrer, M. R. E. (2002). Resumo de direito administrativo. (13a ed). São Paulo: Malheiros. Gallo, S. (2003). Ética e cidadania: caminhos da filosofia. (2003). Campinas: Papirus.

Gil, A. C. (2002). Como elaborar projetos de pesquisa. São Paulo: Atlas.

Hair, J. F., Wolfinbarger, M., David, J. O. \& Bush, R. P. (2010). Fundamentos de pesquisa de marketing. Porto Alegre: Artmed

Heald, D. (2006). Varieties of transparency. Proceedings of the British Academy, 135, 25-43. Recuperado de http://www.davidheald.com/publications/Healdvarieties.pdf.

Instituto Brasileiro de Geografia e Estatística (2010). Censo demográfico 2010. Recuperado de http:// www.censo2010.ibge.gov.br.

International Federation of Accountants. (2001). Governance in the public sector: a governing body perspective. Recuperado de http://www.ifac.org/sites/default/files/publications/files/study-13-governance-in-th.pdf

Lax, J. R. \& Phillips, J. H. (2009). How should we estimate public opinion in the states? American Journal of Political Science, 53(1), pp.107-121. doi 10.1111/1540-5907.2008.00360.x

Mcnellis, C. (2013). How to tell the 'accounting story': balancing competing objectives in accounting communication. The CPA Journal. 83(4), pp. 6-9. Recuperado de http://viewer.zmags.com/publicatio $\mathrm{n} / 78 \mathrm{ed} 02 \mathrm{a} 7 \# / 78 \mathrm{ed} 02 \mathrm{a} 7 / 8$.

Miranda, L. C., Silva, A. J. M., Ribeiro, J. F., Filho \& Silva, L. M. (2008). Uma análise sobre a compreensibilidade das informações contábeis governamentais comunicadas pelo Balanço Orçamentário. Brasilian Business Review, 5(3), pp. 209-228. doi 10.5007/2175.80692010

Moroni, J. A. (2005). Participamos, e daí? Recuperado de http://www.aracati.org.br/portal/pdfs/13_Biblioteca/Textos\%20e\%20artigos/participacao_Moroni.pdf.

Oliveira, A.M. (2005). Avaliação do processo de comunicação entre a contabilidade pública e o usuário da informação: uma abordagem sob o enfoque da teoria da comunicação. Anais do Congresso USP, Controladoria e Contabilidade, São Paulo, SP, Brasil, 5. Recuperado de http://www.congressousp. fipecafi.org/web/artigos52005/360.pdf.

Platt, O. A., Netto, Cruz, F., Ensslin, S. R. \& Ensslin, L. (2007). Publicidade e transparência das contas públicas: obrigatoriedade e abrangência desses princípios na administração pública brasileira. Contabilidade Vista \& Revista, 18(1), pp. 75-94.

Rea, L. M. \& Parker, R. A. (2002). Metodologia de pesquisa. São Paulo: Pioneira.

Reis, J. C. (2007). As identidades do Brasil: de Varnhagen a FHC. Rio de Janeiro: FGV.

Resolução n. 1.374 de 08 de dezembro de 2011. (2008). Dá nova redação à NBC TG Estrutura Conceitual. Diário Oficial da União, Brasília, DF: Conselho Federal de Contabilidade.

Rosa, M. B. (2011). Contabilidade do setor público. São Paulo: Atlas. 
Schedler, A. (1999). Conceptualizing accountability. In A. Schedler, L. Diamond \& M. F. Plattner (Eds.), The self-restraining state: power and accountability in new democracies. Colorado: Lynne Rienner Publishers.

Secretaria do Tesouro Nacional. (2012). Manuais de contabilidade aplicada ao setor público - 2012. (5a ed.) Brasília, DF.

Slomski, V. (2009). Controladoria e governança na gestão pública. São Paulo: Atlas.

Vasile, P., Aristita, R., Cristina, C.-A. \& Mihaela, L. (2009). Accounting - A semiotic process. Economic Science, 3(1), p. 1105.

Weibenberger, B. E. \& Holthoff, G. (2013). Cognitive style and connotative meaning in management accounting communication. Journal of Management Control. 24(1), pp.1-25. doi: 10.1007/s00187013-0172-4.

Yin, R. K. (2010). Estudo de caso: planejamento e métodos. Porto Alegre: Bookman.

Young, I. M. (2006). Representação política, identidade e minorias. Lua Nova: Revista de Cultura Política. (67), pp. 139-190. 